\title{
BMJ Global Health The compatibility of reductionistic and complexity approaches in a sociomedical innovation perspective
}

\author{
Jenneken Naaldenberg (D) , ${ }^{1}$ Noelle Aarts ${ }^{2}$
}

\begin{abstract}
To cite: Naaldenberg J, Aarts N. The compatibility of reductionistic and complexity approaches in a sociomedical innovation perspective. BMJ Global Health 2020;5:e003858. doi:10.1136/ bmjgh-2020-003858
\end{abstract}

Handling editor Seye Abimbola

Received 31 August 2020

Revised 2 November 2020

Accepted 12 November 2020

\section{ABSTRACT}

Medical technologies, e-health and personalised medicine are rapidly changing the healthcare landscape. Successful implementation depends on interactions between the technology, the actors and the context. More traditional reductionistic approaches aim to understand isolated factors and linear cause-effect relations and have difficulties in addressing inter-relatedness and interaction. Complexity theory offers a myriad of approaches that focus specifically on behaviour and mechanisms that emerge from interactions between involved actors and the environment. These approaches work from the assumption that change does not take place in isolation and that interaction and inter-relatedness are central concepts to study. However, developments are proceeding fast and along different lines. This can easily lead to confusion about differences and usefulness in clinical and healthcare research and practice. Next to this, reductionistic and complexity approaches have their own merits and much is to be gained from using both approaches complementary. To this end, we propose three lines in complexity research related to health innovation and discuss ways in which complexity approaches and reductionistic approaches can act compatibly and thereby strengthen research designs for developing, implementing and evaluating health innovations.

\section{THE ROLE OF INTERACTIONS IN HEALTH INNOVATION RESEARCH}

(c) Author(s) (or their employer(s)) 2020. Re-use permitted under CC BY-NC. No commercial re-use. See rights and permissions. Published by BMJ

${ }^{1}$ Primary and Community care, Radboud university medical center, Radboud Institute for Health Sciences, Nijmegen, Gelderland, Netherlands ${ }^{2}$ Institute for Science in Society, Radboud University Nijmegen, Nijmegen, Gelderland, Netherlands

\section{Correspondence to} Dr Jenneken Naaldenberg; jenneken.naaldenberg@ radboudumc.nl
Medical technologies, e-health and personalised medicine are rapidly changing the healthcare landscape and hold great promise in terms of triple aim outcomes: better care, better health and better value. However, worries are being voiced about innovations that are overly expensive, unintendedly lead to increased work pressure, compromise patient safety and privacy, fail to scale up and over-simplify medical issues. Achieving the expected benefits in everyday practice is anything but self-evident. ${ }^{1-3}$ This is not just an implementation issue to be dealt with by maximising facilitators and minimising barriers; rather, it requires changes on many levels and by many involved stakeholders. ${ }^{3}$ It is

\section{Summary box}

Health innovations require a reconfiguration of interdependencies between people and the medical/ healthcare environment and thus of a sociomedical innovation perspective.

- A sociomedical innovation perspective requires a combination of reductionistic and complexity approaches in both research and practice.

- To explore compatibility between reductionistic and complexity approaches, we identify three lines in complexity-based approaches: (1) modelling, (2) reflection and (3) facilitating.

- Distinguishing the characteristics of these three approaches and of a reductionistic approach helps to find the right interplay for a specific project at a specific juncture.

in the interactions between technology, actors and context that desired changes happen. ${ }^{45}$

Historically, health research, including evidence-based medicine and implementation science, has had a reductionistic focus that applies a linear cause-effect approach and aims to understand isolated factors, isolated components or individual behaviour in detail. ${ }^{6}$ Nowadays, a broad landscape of approaches focuses specifically on behaviour and mechanisms that emerge from interactions between involved actors and the environment. ${ }^{7-9}$ Often based on some form of complexity theory, these approaches work from the assumption that change does not take place in isolation and that interaction and inter-relatedness are central concepts to study. In light of COVID-19, it is again clear that intervention and context are inseparable and that randomised controlled trials (RCTs) cannot address everything we need to know. ${ }^{10}$ The body of knowledge on complexity and systems approaches to health and health innovations is growing. ${ }^{11}{ }^{12}$ Developments are proceeding fast and along different lines, resulting in a myriad of approaches that can easily lead to confusion about differences 
and usefulness in clinical and healthcare research and practice.

Reductionistic and complexity approaches each have important merits. Each approach answers different types of research questions, uses different sets of tools and methods, applies different analytical lenses and provides different types of results. Consequently, much is to be gained from using both approaches complementary rather than positioning them as opposites. This paper aims to explore the compatibility of both approaches. To provide more insight into the potential for combining approaches, we first summarise the way reductionist and complexity approaches address interactions and how interactions can influence innovation processes. Next, we propose three complementary lines within complexity research relating to health innovation. Finally, we discuss ways in which complexity approaches and reductionistic approaches can act compatibly from a sociomedical innovation perspective and thereby strengthen research designs for developing, implementing and evaluating health innovations.

\section{INTERACTION IN A SOCIOMEDICAL INNOVATION PERSPECTIVE}

Effective innovation, being either technical or social in nature, requires reconfigurations in interdependencies between people (social environment) and the medical/ healthcare environment. Consequently, a sociomedical innovation perspective asks for insight into these interdependencies and interactions and the way these developed over time. ${ }^{4}$ Using either a complexity or a reductionistic approach influences the framing of a problem and the space for understanding interactions. It influences who will be involved in the process in what role and at what juncture, the data that need to be collected in what way and from whom and the research questions to be answered. For example, a reductionistic causeeffect approach to obesity could result in a focus on a too high energy intake versus a too low energy expenditure, and thus on diet and exercise solutions. In a complexity approach, obesity is considered the outcome of interactions between many systems at multiple levels such as the food system, transportation, school system, built environment etcand so on. ${ }^{12}$ From these interactions emerges, over time, a so-called obesogenic environment. An overall system in which preconditions for obesity are being strengthened, and a focus on environmental intervention. ${ }^{13}$ To provide an overview, the main characteristics of the reductionistic and complexity approaches to change are summarised in table 1 .

Interactions in sociomedical innovations create multicausal patterns. These patterns can help to understand developments and phenomena that cannot be understood by studying individual choices and single causes alone. ${ }^{14}$ Patterns develop over time: decisions generate rules and behaviours that influence subsequent choices (path dependency). In this way, the same initial situation can lead to several outcomes and also that different starting points can still end up with similar results. ${ }^{15}$ Events and decisions in the past influence the course of current developments. Therefore, it is important to know how things have become. Current structures support current practices more than they support envisioned new practices. Being aware of this helps us to understand that change can take a long time to occur and that structures and routines can act as blocking mechanisms. ${ }^{16}$

Configurations such as ways of working, routines and management systems, once established, tend to navigate toward a relatively stable state that is resilient and resists change. This can result in a situation where for a long time there is no reaction to serious attempts to intervene, whereas suddenly a small event could cause a major reaction. ${ }^{1718}$ This phenomenon is also referred to as a tipping point or the drop that makes the cup run over. Figure 1 , by Coleman et al, ${ }^{19}$ illustrates this concept, where B represents the dominant state and the ball (current practice) reacts to changes. Before the ball will tip over to $\mathrm{A}$, it will need a lot of momentum (positive discourse), the 'slope' toward A needs to become shallower (more favourable context), and a strengthened and consolidated A (desired practice) becomes much more attractive. Once a course of action is taken (resulting in B), it is difficult to leave it because choices made immediately result in a configuration of actors, routines and interdependencies that establishes $\mathrm{B}$ as the status quo. ${ }^{4}$

Table 1 Characteristics in reductionistic and complexity approaches to change

\begin{tabular}{ll}
\hline Reductionistic approach to change & Complexity approach to change \\
\hline Knowledge by focusing on part-by-part details & $\begin{array}{l}\text { Knowledge by focusing on interactions, interdependencies and } \\
\text { relationships }\end{array}$ \\
$\begin{array}{l}\text { Problem as a relation of cause and effect } \\
\text { between few parts/actors }\end{array}$ & $\begin{array}{l}\text { Problem as emerging from a system of interactions, relations and } \\
\text { interdependencies between many entities (actors, institutions, context) over } \\
\text { time }\end{array}$ \\
Problem as single events & $\begin{array}{l}\text { Problem as path-dependent patterns over time } \\
\text { Innovation as a process }\end{array}$ \\
$\begin{array}{l}\text { Chnovation as a product to be implemented } \\
\text { evidence-based medicine }\end{array}$ & $\begin{array}{l}\text { Change as emergent behaviour resulting from adaptation, social learning } \\
\text { and self-organisation }\end{array}$ \\
\hline
\end{tabular}




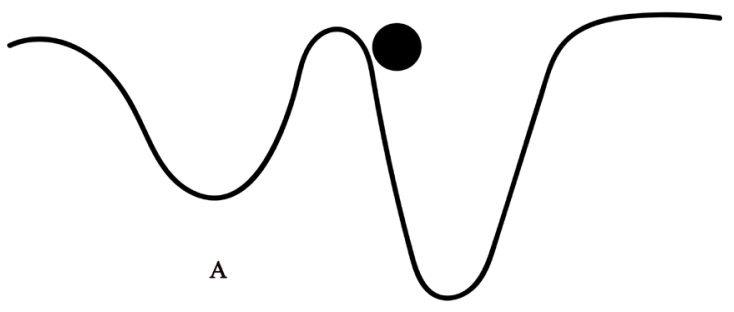

B

Figure 1 Dominant state in a dynamic system. ${ }^{19}$

\section{THREE APPROACHES TO COMPLEXITY IN HEALTH INNOVATION RESEARCH}

Complexity-based approaches all work from the assumptions as summarised in table 1. However, there are large differences in how complexity is operationalised both in health innovation research and in practice. Unfamiliarity with complexity as an approach can easily lead to confusion about usability in research and practice. Especially in light of the aim of this paper, which is to explore compatibility between reductionist and complexity approaches, it is helpful to highlight some key differences. To this end, we identify three lines in commonly used approaches, based on highlighting how approaches can complement each other rather than how they differentiate from each other.

1. Modelling approaches are often computational and focus on complex processes generated by interactions between many actors. The aim is to more accurately capture, model, explain and predict how patterns of interaction influence change and to understand how choices made by individuals result in a collective phenomenon.

2. Reflection approaches focus on what is happening in the interactions and dynamics of innovation processes as produced and represented in frames and narratives. The aim is to understand interactions in change processes and identify blocking mechanisms and preconditions for change.

3. Facilitating approaches are characterised by their actionable components, which aim to facilitate learning and responsiveness during research and implementation processes. Tools are used to actively involve stakeholders and end users to increase the feasibility and meaningfulness of innovations and interventions. Frameworks explicating stakeholders, context, time dimensions and resources are used to gain a rich picture of the project at hand.
COMPATIBILITY TO STRENGTHEN HEALTH INNOVATION

\section{RESEARCH}

Overall, there are good reasons to include some aspects of complexity approaches in health innovation research. However, medical research is traditionally shaped by RCTs and experimental designs that are linear in nature. ${ }^{9} 12$ For well-known reasons, these designs are seen as the gold standard in medical research, but they also implicate that the context should remain as stable as possible, which in daily practice is almost never the case. This reduces the context to an obstacle that needs to be dealt with through the control and isolation of variables. A sociomedical innovation perspective, including both reductionist and complexity approaches as compatible and complementary to each other, can make use of the exiting context by better adapting to initial conditions, available relations and interactions, and existing routines and structures. This helps to understand both resistance to change and space for change, thus increasing the chance of success for innovations.

Different types of knowledge better reflect the innovation processes that research intends to inform and prevents a bias toward types of interventions that are easier to randomise and evaluate. ${ }^{20}$ To benefit from each approach and use complexity approaches where they add most value, table 2 can be used to select the best fit to what a project aims to achieve at a specific juncture. This could result in switching between linear and any of the complexity approaches multiple times. An innovation project could start from a linear approach with a pre-defined technology and set aim. For example, establishing effectiveness of consumer smart watches in supporting health. A shift toward a more complex approach could include an innovation system analysis ${ }^{16}$ to investigate organisational preconditions and the experiences and expectations of stakeholders. These could very well differ between medical specialists, patients, nurses and managers and therefore may influence the development and use of the technology in a positive or a negative way. Insights can be used to create a more favourable innovation context, as both experiences and expectations can be explicated and included in the evaluation. This can be followed by a linear evaluation design (possibly accompanied by a more complexity-oriented process evaluation) that will then deliver relevant outcomes for all involved and prevent the conclusion that a technology or intervention is not effective while it is actually being evaluated on the wrong outcomes or the inappropriate timeframe. ${ }^{12}$ Another example can be found in cases, such as the COVID-19 pandemic, where both types of approaches are called for in order to obtain the required knowledge to act, as Greenhalgh discusses. Drug / vaccine development requires RCT studies, but questions concerning health system resilience, supply chains for protective equipment and the specific spread of infections such as in care homes will benefit from including different 
Table 2 Compatibility in a sociomedical innovation perspective

\begin{tabular}{|c|c|c|c|c|}
\hline & & Complexity approaches & & \\
\hline & Reductionistic approach & Modelling & Reflecting & Facilitating \\
\hline Focus & $\begin{array}{l}\text { Effect size } \\
\text { Prevalence } \\
\text { Causal inference } \\
\text { Predictability } \\
\text { Generalisability }\end{array}$ & $\begin{array}{l}\text { Predict emergence } \\
\text { Explain emergence } \\
\text { Identify leverage points }\end{array}$ & $\begin{array}{l}\text { Identify complexity in } \\
\text { challenges } \\
\text { Explore what happens } \\
\text { Explicate frames and } \\
\text { discourses } \\
\text { Explicate interactions and } \\
\text { relations } \\
\text { Describe structures }\end{array}$ & $\begin{array}{l}\text { Organise learning in } \\
\text { practice } \\
\text { Responsive change } \\
\text { Facilitate networks }\end{array}$ \\
\hline Helps to & $\begin{array}{l}\text { Establish effectiveness } \\
\text { Explain variance } \\
\text { Understand correlation and } \\
\text { causation }\end{array}$ & $\begin{array}{l}\text { Explore scenarios } \\
\text { Understand how choices } \\
\text { made by individuals } \\
\text { result in a collective } \\
\text { phenomenon }\end{array}$ & $\begin{array}{l}\text { Identify starting conditions } \\
\text { Discuss relevant outcomes } \\
\text { Understand perspectives } \\
\text { Identify blocking mechanisms }\end{array}$ & $\begin{array}{l}\text { Engage stakeholders } \\
\text { Conduct inclusive } \\
\text { research } \\
\text { Facilitate group } \\
\text { processes } \\
\text { Increase support }\end{array}$ \\
\hline $\begin{array}{l}\text { Examples } \\
\text { of tools and } \\
\text { methods }\end{array}$ & $\begin{array}{l}\text { Evidence-based medicine } \\
\text { Epidemiology } \\
\text { Randomised controlled } \\
\text { trials } \\
\text { Experimental designs }\end{array}$ & $\begin{array}{l}\text { Agent-based models } \\
\text { Network analysis } \\
\text { Network dynamics } \\
\text { Causal loop models } \\
\text { System dynamics }\end{array}$ & $\begin{array}{l}\text { Innovation systems } \\
\text { Stakeholder analysis } \\
\text { Discourse/narrative analysis } \\
\text { Reflexive practice } \\
\text { Mixed-method case studies }\end{array}$ & $\begin{array}{l}\text { Participatory research } \\
\text { Inclusive research } \\
\text { Soft systems thinking } \\
\text { Design thinking } \\
\text { Natural experiments }\end{array}$ \\
\hline
\end{tabular}

types of knowledge beyond the knowledge that can be derived from RCTs. ${ }^{10}$

\section{CONCLUSION}

In this paper, we have argued that, for health innovations to be successful, reductionistic approaches and complexity approaches should be seen as complementary. We have distinguished three different lines in complexity research that can be of use at different times in a project depending on the type of challenge that arises at a certain juncture. For medical specialists and engineers, who often work on cutting edge innovations, focusing on a technology is a more natural part of their work than focusing on social interactions and interdependencies. In table 2, we illustrate that both complex and linear approaches have their merits and can be complementary and compatible. Multiple tools, methods and approaches are available to facilitate the integration of sociomedical interactions in health innovation research. This paper may help find the right interplay between approaches for a specific project at a specific juncture. Together, these approaches facilitate the ability to generate different types of knowledge needed to gain a rich understanding of sociomedical interactions and facilitate change and innovation in 21 st century healthcare.

Twitter Jenneken Naaldenberg @jnaaldenberg

Acknowledgements JN would like to acknowledge academic collaborative 'stronger on your own feet' for their support and Dr Hilde Tobi for her feedback on a previous draft of this article.

Contributors $\mathrm{JN}$ is a health scientist and senior researcher in health for people with intellectual disabilities. NA is a professor of socioecological interactions and studies inter-human processes and communication for creating space for sustainable change. This article originates from discussions between JN and NA exploring how socioecological interactions could also apply to the health and medical innovation system. JN drafted the first version of this paper based on literature from health and medical research, socioecological research and innovation studies. JN acts as the guarantor. NA added conceptual insights and commented and amended drafts of the paper. Both authors approved the final manuscript.

Funding The authors have not declared a specific grant for this research from any funding agency in the public, commercial or not-for-profit sectors.

Competing interests None declared.

Patient and public involvement Patients and/or the public were not involved in the design, or conduct, or reporting, or dissemination plans of this research.

Patient consent for publication Not required.

Provenance and peer review Not commissioned; externally peer reviewed.

Data availability statement There are no data in this work.

Open access This is an open access article distributed in accordance with the Creative Commons Attribution Non Commercial (CC BY-NC 4.0) license, which permits others to distribute, remix, adapt, build upon this work non-commercially, and license their derivative works on different terms, provided the original work is properly cited, appropriate credit is given, any changes made indicated, and the use is non-commercial. See: http://creativecommons.org/licenses/by-nc/4.0/.

\section{ORCID iD}

Jenneken Naaldenberg http://orcid.org/0000-0003-2675-4516

\section{REFERENCES}

1 Murray E. eHealth: where next? Br J Gen Pract 2014;64:325-6.

2 Catwell L, Sheikh A. Evaluating eHealth interventions: the need for continuous systemic evaluation. PLoS Med 2009;6:e1000126.

3 Greenhalgh T, Papoutsi C. Spreading and scaling up innovation and improvement. BMJ 2019;365:I2068.

4 Aarts N. Dynamics and dependence in socio-ecological interactions. Radboud University: Nijmegen, 2018. https://hdl.handle.net/2066/ 197147

5 Smits R. Innovation studies in the 21st century: questions from a user's perspective. Technol Forecast Soc Change 2002;69:861-83.

6 Greenhalgh T. How to read a paper: the basics of evidence-based medicine and healthcare. 6th edn. Oxford: Wiley, 2019.

7 de Savigny D, Blanchet K, Adam T. Applied systems thinking for health systems research, a methodological Handbook. London, England: McGraw-Hill Education, 2017.

8 Peters DH. The application of systems thinking in health: why use systems thinking? Health Res Policy Syst 2014;12:51. 
9 Greenhalgh T, Papoutsi C. Studying complexity in health services research: desperately seeking an overdue paradigm shift. BMC Med 2018;16:95.

10 Greenhalgh T. Will COVID-19 be evidence-based medicine's nemesis? PLoS Med 2020;17:e1003266.

11 Carey G, Malbon E, Carey N, et al. Systems science and systems thinking for public health: a systematic review of the field. BMJ Open 2015;5:e009002.

12 Rutter H, Savona N, Glonti K, et al. The need for a complex systems model of evidence for public health. Lancet 2017;390:2602-4.

13 Swinburn B, Egger G, Raza F. Dissecting obesogenic environments: the development and application of a framework for identifying and prioritizing environmental interventions for obesity. Prev Med 1999;29:563-70.

14 Christakis NA, Fowler JH. The collective dynamics of smoking in a large social network. N Engl J Med 2008;358:2249-58.
15 Diez Roux AV. Complex systems thinking and current impasses in health disparities research. Am J Public Health 2011;101:1627-34.

16 Klein Woolthuis R, Lankhuizen M, Gilsing V. A system failure framework for innovation policy design. Technovation 2005;25:609-19.

17 Braithwaite J. Changing how we think about healthcare improvement. BMJ 2018;361:k2014.

18 Paina L, Peters DH. Understanding pathways for scaling up health services through the lens of complex adaptive systems. Health Policy Plan 2012;27:365-73.

19 Coleman PT, Vallacher RR, Nowak A, et al. Intractable conflict as an attractor: a dynamical systems approach to conflict escalation and intractability. Am Behav Sci 2007:50:1454-75.

20 Ogilvie D, Adams J, Bauman A, et al. Using natural experimental studies to guide public health action: turning the evidence-based medicine paradigm on its head. $J$ Epidemiol Community Health 2020;74:203-8. 